\title{
Biogeography and Diversity of Multi-Trophic Root Zone Microbiomes in Michigan Apple Orchards: Analysis of Rootstock, Scion, and Local Growing Region
}

\author{
A. F. Bintarti, ${ }^{1}$ J. K. Wilson, ${ }^{2}$ M. A. Quintanilla-Tornel, ${ }^{2}$ and A. Shade ${ }^{1,3, \dagger}$ \\ ${ }^{1}$ Department of Plant, Soil and Microbial Sciences, Michigan State University, East Lansing, MI 48824 \\ ${ }^{2}$ Department of Entomology, Michigan State University, East Lansing, Ml 48824 \\ ${ }^{3}$ Department of Microbiology and Molecular Genetics, Plant Resilience Institute, DOE Great Lakes Bioenergy Research Center, and Program \\ in Ecology, Evolution, and Behavior, Michigan State University, East Lansing, MI 48824
}

Accepted for publication 12 March 2020.

\section{ABSTRACT}

Soil is a highly heterogeneous environment with many physical and chemical factors that are expected to vary within and across fruit orchards, and many of these factors also drive changes in the soil microbiome. To understand how biogeography influences apple root microbiomes, we characterized the bacterial and archaeal, fungal, nematode, oligochaete, and mycorrhizal communities of the root zone soil (soil adjacent to the tree trunk and expected to be influenced by the plant) across 20 sites that represent the main Michigan appleproducing region. Amplicon sequencing of the $16 \mathrm{~S}$ rRNA and internal transcribed spacer genes were performed, as well as direct quantification of nematodes, oligochaetes, and mycorrhizal fungi with microscopy. The microbiome community structures were affected by site and rootstock, but not by scion. Microbiomes had taxa typical of soil, including an archaeal taxon affiliated with family Nitrososphaeraceae, bacterial phyla Proteobacteria and
Acidobacteria, and fungal phyla Ascomycota and Basidiomycota. While many taxa were detected in all samples and collectively composed $41.55 \%$ of the relative abundances, they had average relative abundances each of less than $1 \%$, with no notable dominance. We used network analysis to understand potential for intertrophic interactions, but detected few cross-kingdom associations. Together, these results show the complexity of the apple root zone microbiome and did not identify obvious biotargets that may universally associate with tree health. This suggests that the key attributes of the apple root zone community may be in the communitylevel functional traits that are shared and distributed across the membership, rather than by its composition.

Keywords: 16S rRNA, archaea, bacteria, ecology, metagenomics, microbiome, microorganism, mycology, nematode, ITS, root zone
Soil microbial communities have been known to play an important role for plant growth and fitness (Sugiyama et al. 2013), enhancing plant nutrient acquisition (Weidner et al. 2015), inducing flowering time (Panke-Buisse et al. 2015), improving plant tolerance against abiotic stresses (Meena et al. 2017), and promoting pathogen resistance (Chapelle et al. 2016). The plant and soil-associated microbiome

\section{${ }^{\dagger}$ Corresponding author; A. Shade: shadeash@msu.edu}

Funding: This work was supported in part by grants from the National Institute of Food and Agriculture Michigan State University Project AgBioResearch and Project GREEEN GR17-034 and the Michigan Apple Committee. A. Shade acknowledges support from the USDA-National Institute of Food and Agriculture Michigan State AgBioResearch.

*The $e$-Xtra logo stands for "electronic extra" and indicates that supplementary material and supplementary tables are published online.

The author(s) declare no conflict of interest.

(C) 2020 The American Phytopathological Society. includes numerous players that are expected to interact with each other either directly or through trophic cascades and multitrophic interactions (Thakur and Geisen 2019; Wei et al. 2015). Multitrophic phytobiome interactions can involve bacteria, archaea, fungi, and nematodes that reside in plant-associated soils and on or in the plant itself. However, these multiple players are rarely investigated as a system within the same study. Additionally, changes in soil edaphic factors, such as $\mathrm{pH}$, texture, and organic matter content, are known to drive microbiome assembly over space, including in managed systems such as fruit orchards (Deakin et al. 2018; Jiang et al. 2017). Taken together, it is expected that the host plant, as well as abiotic soil characteristics and biotic, multiplayer microbial interactions engage in feedbacks that ultimately shape the microbial community and determine its interactions with the plant.

The objective of our study is to assess the biogeography of bacterial, archaeal, fungal, and nematode communities in the root zone of apple trees, and to determine their relationships with each other and their changes over natural abiotic gradients across orchards. We collected root zone samples from 20 mature commercial 
apple orchards in Michigan. Although Michigan is ranked third in the United States in terms of apple production with 1.07 billion pounds of apples valued on average at \$297 million per year (U.S. Department of Agriculture-National Agricultural Statistics Service 2019), microbiome-apple relationships have not been investigated here. We used high-throughput amplicon sequencing to assess bacterial and archaeal, and fungal communities, and microscopy to identify nematodes, oligochaetes and mycorrhizal fungi. The results uncover possible interactions between these important apple root zone community members and provide foundational baseline information on microbiome diversity and putative phytobiome interactions prior to anticipated apple tree removal and replant on these farms.

\section{MATERIALS AND METHODS}

Survey design, soil sample collection, and apple rootstocks and scions. Forty-five root zone soil samples were collected from 20 mature (i.e., at least 10 years old) apple orchards in Michigan in June 2017 (Supplementary Fig. S1). These orchards were selected first because they are representative of an area considered to be prime orchard ground where apples have been grown for as many as six generations on family farms, and second because they offered a key comparison across known local differences in soil edaphic characteristics. Each orchard was considered as an experimental unit for understanding biogeography, and statistical comparisons were made across orchards to assess spatial dynamics and both within and across orchards to assess influence of different rootstock and scion varieties. Within an orchard, each distinct combination of apple rootstock and scion was planted in a different tree row. Soil cores were collected from the bases of each of 10 trees in a single tree row (e.g., trees with the same rootstock/scion combination). These soil cores were composited into a homogenized soil sample to represent the tree row and rootstock/scion combination. Soil cores (20 cm depth $\times 2.5 \mathrm{~cm}$ diameter) were used to collect root zone samples and were cored within 15 to $20 \mathrm{~cm}$ of the base of a tree trunk. By "root zone," we mean the local soil surrounding and adjacent to the plant and its root structures that is expected to be chemically and physically influenced by the plant via exudates, stemflow, etc. As a qualifier, the exact quantities and rates of root exudation were not measured. The soil corer was sprayed and wiped with $70 \%$ ethanol before sample collection to prevent cross-site microbial contamination. Soil core composites were collected into Whirl-Pak sample bags and immediately placed on ice for transport. In the laboratory, soils were sieved through $4 \mathrm{~mm}$ mesh to remove large pieces of rocks, and root tissue, and other plant residues. Sieved soil was stored at $-80^{\circ} \mathrm{C}$ until microbial DNA extraction. One hundred grams of each soil sample was sent to the Michigan State University Soil and Plant Nutrient Laboratory for soil physicochemical testing. The analysis of soil chemistry and characteristics were conducted to provide us more information and knowledge in assessing root zone microbial community in apple orchards. Soil chemistry and characteristics also allow us to decipher the influence of environmental factors to the microbial community structure and diversity. Soil parameters including $\mathrm{pH}$, lime index, phosphorus $(\mathrm{P})$, potassium $(\mathrm{K})$, calcium $(\mathrm{Ca})$, magnesium $(\mathrm{Mg})$, nitrate $\left(\mathrm{NO}_{3} \mathrm{~N}\right)$, ammonium $\left(\mathrm{NH}_{4} \mathrm{~N}\right)$, organic matter $(\mathrm{OM})$, sand, silt, clay, and soil type were measured from all samples. Full metadata, including growing locations, soil environmental characteristics, and scion and rootstock information can be found in Supplementary Table S1.

Nematode, oligochaete, and mycorrhizal fungal quantification. The abundances of nematodes, oligochaetes, and mycorrhizal fungi were assessed using standard protocols of the Michigan State Plant and
Pest Diagnostic Laboratory. Nematodes, mycorrhizal fungi, and oligochaetes were removed from the soil with a modified centrifugation and flotation method (Jenkins 1983). One hundred grams of soil was suspended in water and then poured over sieves that were nested in mesh size, allowing soil particles to pass through but capturing the nematodes, oligochaetes, and mycorrhizal fungi spores. These samples then were centrifuged, and water was decanted and replaced with $61.5 \%$ sucrose. The sample was centrifuged again to capture the microbial groups in the sucrose gradient to separate them from any remaining soil particles. Nematodes, mycorrhizal spores, and oligochaetes were removed from the sucrose, rinsed, and then finally identified using inverted microscopy at 200x magnification. Nematodes were identified to the lowest level of taxonomic classification possible, with most identifications possible at the genus level. Mycorrhizal spores and oligochaetes individuals were counted but not taxonomically identified.

Microbial DNA extraction and PCR amplification. Microbial DNA extraction was carried out for $0.25 \mathrm{~g}$ of each soil sample using the manufacturer's protocol of PowerSoil DNA Isolation Kit (MoBio Laboratories, Solana Beach, CA, U.S.A.). The soil DNA was then quantified using Qubit dsDNA BR Assay Kit (ThermoFisher Scientific, Waltham, MA, U.S.A.) to determine the concentration. Polymerase chain reaction (PCR) was conducted to verify the amplification of the V4 region of bacterial and archaeal $16 \mathrm{~S}$ rRNA gene using 515f (5'-GTGCCAGCMGCCGCGGTAA$3^{\prime}$ ) and 806r (5'-GGACTACHVGGGTWTCTAAT-3') universal primers (Caporaso et al. 2011). The 16S rRNA gene amplification was conducted under following condition: $94^{\circ} \mathrm{C}$ for $3 \mathrm{~min}$, followed by 35 cycles of $94^{\circ} \mathrm{C}(45 \mathrm{~s}), 50^{\circ} \mathrm{C}(60 \mathrm{~s})$, and $72^{\circ} \mathrm{C}(90 \mathrm{~s})$, with a final extension at $72^{\circ} \mathrm{C}(10 \mathrm{~min})$. The amplification was performed in $25 \mu \mathrm{l}$ mixture containing $12.5 \mu \mathrm{l}$ of GoTaq Green Master Mix (Promega, Madison, WI, U.S.A.), $0.625 \mu \mathrm{l}$ of each primer $(20 \mathrm{mM})$, $1 \mu \mathrm{l}$ of DNA template $(\sim 15 \mathrm{ng}$ per $\mu \mathrm{l})$, and $10.25 \mu \mathrm{l}$ of nucleasefree water. The amplicons were diluted to the concentration of 10 to 20 nanogram per $\mu 1$ then sequenced using Illumina MiSeq platform at the Research Technology Support Facility (RTSF) Genomics Core, Michigan State sequencing facility.

Fungal communities were detected by PCR amplification of ITS1 region using ITS1f (5'-CTTGGTCATTTAGAGGAAGTAA-3') and ITS2 (5'-GCTGCGTTCTTCATCGATGC-3') primer pair (Smith and Peay 2014) with addition of index adapters as required by the RTSF Genomics Core (https://rtsf.natsci.msu.edu/genomics/ sample-requirements/illumina-sequencing-sample-requirements/). The PCR conditions for ITS1 amplification are as follows: $94^{\circ} \mathrm{C}$ for $3 \mathrm{~min}$, followed by 35 cycles of $94^{\circ} \mathrm{C}(30 \mathrm{~s}), 63.5^{\circ} \mathrm{C}$ for $(30 \mathrm{~s})$, and $72^{\circ} \mathrm{C}$ for $(30 \mathrm{~s})$, with a final extension at $72^{\circ} \mathrm{C}$ for $10 \mathrm{~min}$. The amplification was performed in $50 \mu \mathrm{l}$ mixture containing $20 \mu \mathrm{l}$ of GoTaqGreen Master Mix (Promega), $1 \mu$ l of each primer $(10 \mathrm{mM})$, $1 \mu \mathrm{l}$ of DNA template $(\sim 15 \mathrm{ng}$ per $\mu \mathrm{l})$, and $27 \mu \mathrm{l}$ of nuclease-free water. PCR products were purified using the manufacturer's protocol of WizardSV Gel and PCR Clean-Up System (Promega), and then quantified using Qubit dsDNA BR Assay Kit (ThermoFisher Scientific). Purified PCR products with the concentration range 2 to $10 \mathrm{ng}$ per $\mu \mathrm{l}$ were sequenced at the RTSF Genomics Core using Ilumina MiSeq platform. The 16S and ITS libraries were prepared using the Illumina TruSeq Nano DNA Library Prep Kit. Ilumina MiSeq was run using v2 Standard and paired-end reads sequencing format $(2 \times 250 \mathrm{bp})$.

Sequencing data analysis and operational taxonomic unit (OTU) clustering. Bacterial and archaeal raw reads produced from Illumina MiSeq were processed using USEARCH (v10.0.240). Preparation of raw reads was performed using the protocol established in the USEARCH pipeline followed by OTUs clustering using UPARSE method (Edgar 2013), and then further analyses 
were conducted using QIIME1 (v1.9.1) (Caporaso et al. 2010). Read preparation and processing used in this study consisted of paired end reads merging, filtering the low-quality sequences, dereplication to find unique sequences, singleton removal, denoising (preclustering) via cluster_fast command which implements UNOISE algorithm and chimera checking (Edgar and Flyvbjerg 2015). OTU picking was conducted using open reference strategy as described in the previous study (Lee et al. 2017). First, closed reference OTU picking was performed at $97 \%$ identity threshold by clustering quality filtered reads against the SILVA database (v1.32) (Quast et al. 2013) using usearch_global command. Later, reads that failed to hit the SILVA reference were clustered de novo at $97 \%$ identity using cluster_otus command, which also detected chimera. Thus, the OTUs generated by closed reference and de novo OTU picking were combined to make the full set of OTU representative sequences. Finally, all pre-dereplicated sequences were mapped back to the full set of OTU representative sequences to build an OTU table. The next analyses, performed in QIIME1, included taxonomic assignment to the reference data sets of SILVA (v.1.32) database using UCLUST algorithm at a minimum confidence of 0.9 (the default method) (Edgar 2010), and eukaryotic (chloroplast and mitochondria) sequence removal from OTU table. Read quality control and filtering generated 1,786,268 bacterial/ archaeal reads in total. Rarefaction to the lowest sequencing depth (27,716 bacterial/archaeal reads) was conducted to standardize the sampling efforts using single_rarefaction.py command in QIIME1 (Gihring et al. 2012; Weiss et al. 2017).

The processing of fungal ITS raw reads was also conducted using USEARCH (v10.0.240) pipeline. Reads preprocessing including reads merging, primer removal using cutadapt (v1.17) (Martin 2011), filtering and trimming using fastq_filter command, and reads dereplication to find unique sequences. Quality filtered reads then clustered into OTUs using the same approach as described above which was open reference OTU picking using UNITE fungal ITS database (v.7.2) (Kõljalg et al. 2013) with 97\% of identity threshold. The OTU table was built by mapping pre-dereplicated sequences back to the full set of OTU representative sequences obtained from open reference OTU picking. Fungal taxonomic classification was performed using CONSTAX tool (Gdanetz et al. 2017), which compares three taxonomic assignment tools for fungal sequence data: RDP Classifier (Cole et al. 2014; Wang et al. 2007), UTAX (Edgar 2010, 2013), and SINTAX (Edgar 2016). The CONSTAX tool generates an improved consensus taxonomic file which is a combination among those three programs and the reference used for taxonomic assignment in this tool is UNITE fungal ITS database (v.7.2). The ITS gene taxonomic classification was performed at a minimum confidence of 0.8 . Read quality control and filtering generated 4,240,062 fungal reads in total. Subsamples of sequence was conducted by rarefying to the lowest number of sequence (56,240 fungal reads) (Gihring et al. 2012; Weiss et al. 2017) using single_rarefaction.py command in QIIME1 (v1.9.1).

Microbial community analysis. Microbial community analyses were conducted in the $\mathrm{R}$ environment for statistical computing (v3.5.1) (R Core Development Team). Microbial composition and relative abundance of each sample and block was analyzed using Phyloseq package (v1.26.1) (McMurdie and Holmes 2013). Alpha diversity indices (Pielou's evenness, total species number or richness) and beta diversity of microbial community were calculated on the rarefied OTU table using the vegan package (v2.5-4) (Oksanen et al. 2019). We chose these two metrics because they complement one another in the information they provide: richness reveals the total number of taxa without accounting for their differences in abundances, while Pielou's evenness considers the equitability of taxon abundance. However, we found that the overarching patterns of these two metrics largely agree.
The difference of bacterial and archaeal, and fungal alpha diversity among sites, rootstocks, and scions were evaluated using one-way analysis of variance (ANOVA) and Tukey's honestly significant difference (HSD) post-hoc test. The normality and homoscedasticity of the data were verified using Saphiro-Wilk and Levene's test, respectively. Nonparametric Kruskal-Wallis test and post-hoc Dunn's test with Benjamini-Hochberg correction for $P$ values were performed when the normality assumptions of one-way ANOVA were not met. Welch's ANOVA and Games-Howell posthoc tests were conducted for the data that did not meet the homoscedasticity assumption. The differences of nematode, oligochaete, and mycorrhizal fungi abundances among sites, rootstocks, and scions were assessed using one-way ANOVA and Tukey's HSD post-hoc test. Nematodes and oligochaetes count data were square-root-transformed. The mycorrhizal fungi count data were $\log _{10}$-transformed to meet test assumptions. Alpha diversity metrics of nematodes including richness and Pielou's evenness were calculated using untransformed count data. Pearson correlation and regression analysis were conducted to see the relationship between microbial alpha diversity and all parameters (soil characteristics, nematodes, oligochaetes, and mycorrhizal fungi abundances).

Beta diversity was calculated using Bray-Curtis dissimilarity indices and visualized with principal coordinate analysis (PCoA). The environmental variables were fitted into PCoA plot and tested for their significance using permutation tests using 'envfit' function in vegan package (v2.5-4) (Oksanen et al. 2019). Permutational multivariate analysis of variance (PERMANOVA) was performed to assess the effects of different factors on the microbial community structure. We performed Mantel test to assess the correlation between geographic distance with bacterial/archaeal, fungal, and nematode distance matrices (Guillot and Rousset 2013). The PCoA ordinates of bacterial/archaeal, fungal, and nematode communities were also compared and tested using Procrustes rotation with PROTEST (Oksanen 2015) to analyze the congruence between two community ordinations. Core microbiota of apple root-zone soil was also assessed by assessing the microbial OTUs' abundances versus their occupancies (Grady et al. 2019).

Network analysis. The network was constructed based on random matrix theory methods (Deng et al. 2012). We combined the bacterial and archaeal, and fungal OTUs and nematodes, mycorrhizal fungi, and oligochaetes count number and ran the data through the Molecular Ecological Network Analysis (MENA) Pipeline (Deng et al. 2012) on the website (http://ieg4.rccc.ou.edu/ mena) of the University of Oklahoma's Institute for Environmental Genomics. The network construction was conducted as the following setting: OTUs detected in 23 out of 45 total samples were selected ( $\sim 50 \%$ occupancy), blanks with paired valid values were filled with 0.01 , logarithm values were calculated, Pearson correlation coefficient was used for similarity matrix method, calculation order was conducted by decreasing the cutoff from top and only Poisson regression was used. We used greedy modularity optimization for separation method and calculate $\mathrm{Zi}$ (within-module connectivity) and Pi (among-module connectivity) values to identify the modularity. Module and network hubs, peripherals, and connectors of the network were determined by $\mathrm{Zi}$ and $\mathrm{Pi}$ value of 2.5 and 0.62 , respectively. The visualization of network was conducted using Cytoscape software (v.3.7.1) (Shannon et al. 2003).

Data and code availability. The computational workflows for sequence processing and ecological statistics are available on GitHub (https://github.com/ShadeLab/PAPER_Bintarti_2020_Phytobiomes/). Raw sequence data of bacteria/archaea and fungi have been deposited in the Sequence Read Archive NCBI database under accession number PRJNA507629. 


\section{RESULTS}

Sequencing summary. A total of 1,786,268 and 4,240,062 quality controlled bacterial/archaeal and fungal reads were obtained from 45 root zone soil samples across 20 orchards in Michigan. Each community was subsampled to the minimum number of quality sequences observed to construct the taxon table (27,716 and 56,240 of bacterial/archaeal and fungal reads, respectively). OTUs were defined at $97 \% 16 \mathrm{~S}$ rRNA and ITS gene sequence identity threshold resulting in 22,510 and 3,553 bacterial/archaeal and fungal total OTUs, respectively. Rarefaction curves indicated that the sequencing depth was sufficient to observe all taxa and microbial community in the sample (Supplementary Fig. S2).

Bacterial and fungal alpha diversity among sites, rootstocks, and scions. We assessed the alpha (within-sample) diversity among sites, rootstocks, and scions for the dominant trophic groups within the microbial ecosystem, including bacteria and archaea, and fungi assessed using sequencing of phylogenetic marker genes, and nematodes, oligochaetes, and mycorrhizal fungi assessed using traditional soil microscopy and counting. This allowed us to relate players from different trophic levels to one another in their occurrences and use them as explanatory variables for the biogeographic patterns observed.

There were overall differences in bacterial and archaeal richness and Pielou's evenness among sites and rootstocks (Supplementary Fig. S3A, Fig. 1A, Kruskal-Wallis and ANOVA results, Table 1). Site-by-site comparisons revealed that there were alpha diversity differences among five orchards, sites 1, 3, 13, 15, and 18 (Supplementary Table S2). Rootstock-by-rootstock comparisons for richness were not significant, suggesting that any differences detected were marginal (Supplementary Table S3); however, there were pairwise rootstock differences in Pielou's evenness (Supplementary Table S3). Specifically, root zone soil of Bud 9 and M7 rootstocks had higher bacterial and archaeal Pielou's evenness compared with M26 and M9.

There were correlations between bacterial and archaeal alpha diversity with soil texture and soil chemical properties as indicated by linear regression model (Supplementary Table S4; Supplementary Fig. S4). Sand content positively correlated with the alpha diversity; meanwhile, silt and clay content negatively correlated with the alpha diversity. Moreover, soil type also had an impact on the bacterial and archaeal richness (Welch's ANOVA, F-stat $=$ $13.568, \mathrm{df}=2, n=3, P=0.01)$. Sandy loam soil had higher bacterial and archaeal richness compared with loam (Games-Howell posthoc test, $P=0.002$ ) and sandy clay loam soil (Games-Howell posthoc test, $P=0.008$ ). These results suggested that soil with coarser and sandy texture are likely to harbor more diverse microbes than soil with finer texture. Among soil chemical properties tested, bacterial and archaeal alpha diversity positively correlated with $\mathrm{P}$ and negatively correlated with $\mathrm{K}$ and $\mathrm{Ca}$, indicating that these communities likely play a role in macro- and micronutrient cycles in soil, including in P solubilization.

Similar to the bacterial and archaeal alpha diversity patterns, there were differences of fungal richness among sites and rootstocks, but there were no differences of Pielou's evenness (Table 1, Supplementary Fig. S3B, Fig. 1B). Specifically, site 17 had higher fungal richness than almost half of other sites (Supplementary Table S5). Soil taken from M26 root zones had lower fungal richness than Bud 9. On balance, M126 rootstock had higher fungal richness compared with most of the rootstocks (Supplementary Table S6).

\section{A Bacteria/archaea}
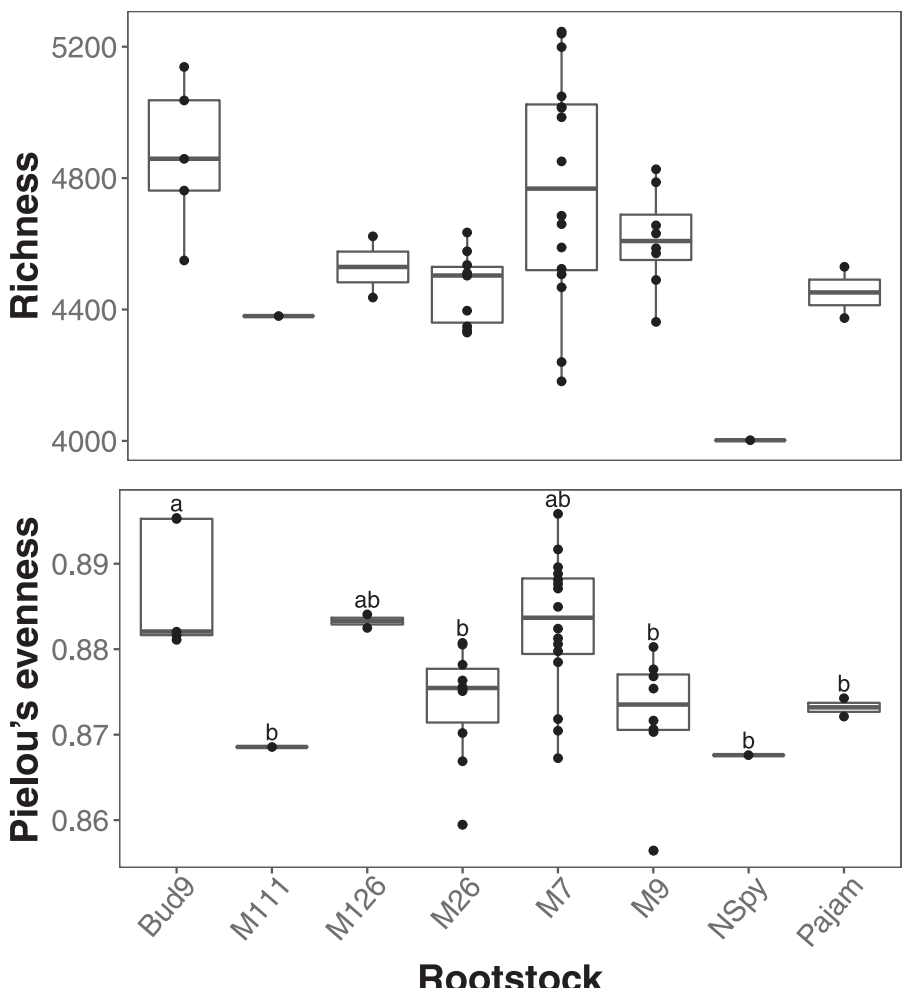

\section{B Fungi}
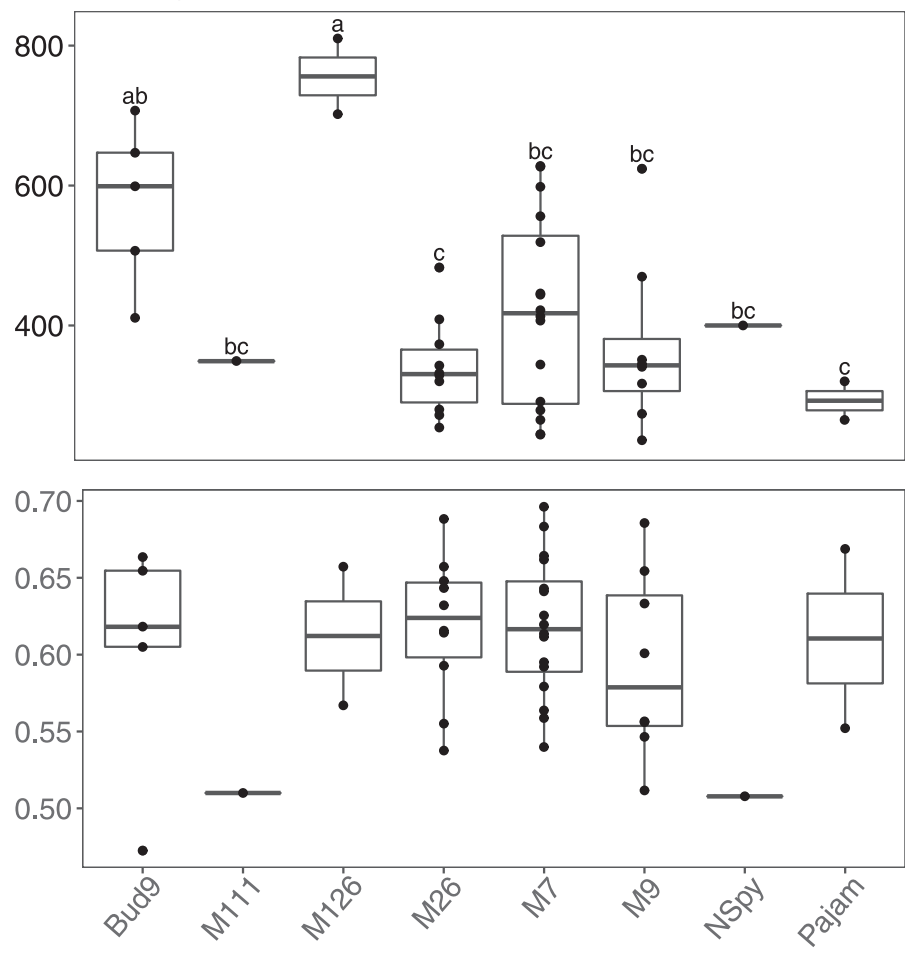

Rootstock

Fig. 1. Alpha diversity metrics of A, bacteria/archaea and B, fungi: richness (operational taxonomic unit number, clustered at $97 \%$ identity threshold) and Pielou's evenness among rootstocks. For each boxplot, circles represent measurement for each sample. The central horizontal lines represent the mean of measurements. Boxes labeled with different letters are identified as significantly different based on Tukey's honestly significant difference post-hoc test. Boxes without label are not significantly different. 
Soil chemistry and texture only correlated with fungal Pielou's evenness and not richness (Supplementary Table S4; Supplementary Fig. S5). Similar to what was observed for bacterial and archaeal alpha diversity, fungal evenness was positively correlated with sand content and negatively correlated with silt content. Soil type also affected fungal evenness (one-way ANOVA, F-stat $=4.027, \mathrm{df}=2, n=3, P=$ 0.02 ), and, again, similar to bacteria and archaea, sandy loam soil had higher fungal evenness than loam soil (Tukey's HSD post-hoc test, $P=0.02$ ). Among soil chemical properties tested, fungal Pielou's evenness negatively correlated with $\mathrm{K}$ and $\mathrm{Mg}$ content.

Nematodes and other groups: Alpha diversity. Other soil trophic levels counted from the apple root zone included 11 trophic groups of nematodes that are classified based on their feeding habits (including bacterivores, herbivores, omnivores, carnivores, and fungivores), mycorrhizal fungi, and oligochaetes. A total count of 31,820 nematodes, 3,420 mycorrhizal fungi, and 544 oligochaetes were observed. Mean of total count showed that the nematode group Rhabditidae had the highest absolute abundance compared with others $(560.9 \pm 480.86$, SD as well as highest prevalence $(100 \%)$ (Supplementary Tables S7 and S8). In addition, the distribution of nematodes and other soil trophic levels revealed that mycorrhizal fungi were found in all soil samples (100\%), followed by Tylenchus (97.77\%), Dorylaimidae (88.88\%), Aphelenchus (86.66\%), oligochaetes $(82.22 \%)$, Xiphinema spp. (also known as dagger nematodes; $73.33 \%$ ), and Pratylenchus spp. (also known as lesion nematodes; 53.33\%) (Supplementary Table S8). Among these groups, Xiphinema spp. and Pratylenchus spp. belong to plantparasitic nematodes.

Total absolute nematode abundances among sites showed $P=$ 0.057 (ANOVA). Significant differences in the total absolute abundance of nematodes were also detected among rootstocks (ANOVA, F-stat $=2.69, \mathrm{df}=7, n=8, P=0.02$ ) but not scions (ANOVA, $P>0.05$ ). The comparison analysis showed that NSpy and Bud9 root zone had higher nematode abundances than Pajam (Tukey's HSD post-hoc test, $P=0.02$ and 0.03 , respectively) (Fig. 2, Supplementary Table S9). Moreover, significant differences in oligochaetes and mycorrhizal fungi abundances were detected among sites (ANOVA, F-stat $=3.45$ and 3.46, respectively, $\mathrm{df}=19$, $n=20, P=0.002$ ) and site 17 had higher oligochaetes abundance than almost half of the other sites (Tukey's HSD post-hoc test, $P<$ 0.05) (Fig. 2, Supplementary Table S10). Site to site comparison showed that site 8 had lower mycorrhizal fungi abundances than several other sites (Tukey's HSD post-hoc test, $P<0.05$ ) (Fig. 2, Supplementary Table S11). The differences of absolute oligochaetes abundance among rootstocks had $P=0.054$ (ANOVA).

We further tested the correlation of nematode, mycorrhizal fungi, and oligochaetes abundances to the microbial alpha diversity. The nematode group Tylenchus negatively correlated with bacterial and archaeal alpha diversity, meanwhile Rhabditidae positively correlated with bacterial and archaeal evenness (Supplementary Fig. S4). In contrast, there were no correlations identified between fungal alpha diversity and absolute abundances of other trophic levels. Nematode alpha diversity showed no differences among sites, rootstocks, or scions (ANOVA, $P>0.05$ ). Furthermore, we tested the correlation between nematodes and bacterial and archaeal and fungal alpha diversity metrics. Nematode Pielou's evenness negatively correlated with bacterial and archaeal Pielou's evenness (Supplementary Fig. S6).

From all the analyses, there were no differences between bacterial and archaeal, fungal, and nematode alpha diversity among scions (ANOVA, $P>0.05$ ), suggesting that the above-ground scion has marginal influence on the root zone microbiome. Those results indicated that root zone microbial communities were varied among different apple orchard locations and were also influenced by the variety of the rootstock planted by the growers.

Microbial beta diversity. Soil $\mathrm{pH}$, lime index, $\mathrm{Ca}, \mathrm{Mg}$, sand, and silt content as well as a nematode group, Tylenchus, had explanatory value for describing the patterns in beta diversity among bacterial and archaeal communities (Table 2) (Supplementary Fig. S7A). For fungi, soil $\mathrm{pH}$, lime index, $\mathrm{Mg}$ content, and nematode groups of Pratylenchus spp. and Tylenchus had explanatory value (Table 2) (Supplementary Fig. S7B). There were no distinct separations of microbial communities by orchard site or apple rootstock. However, on balance, communities from similar sites or rootstocks were proximal to each other, especially for bacterial and archaeal PCoA plots (Supplementary Figs. S7 and S8). Permutated multivariate analysis of variance (PERMANOVA) revealed that bacterial/ archaeal and fungal community structure and composition were influenced by site $\left(\mathrm{F}\right.$-stat $=1.88, R^{2}=0.58, P=0.001$ and F-stat $=$ $1.68, R^{2}=0.56, P=0.001$, respectively $)$ and rootstock $(\mathrm{F}$-stat $=1.48$, $R^{2}=0.21, P=0.004$ and F-stat $=1.35, R^{2}=0.20, P=0.006$, respectively), but not by scion $(P>0.05)$. We also calculated the effect of interaction between variables (site and rootstock) to the microbial beta diversity. We detected differences of microbial beta diversity among different sites with the same rootstock (PERMANOVA, $P<$ $0.05)$. In contrast, there were no differences of microbial beta diversity among different rootstocks in the same site (PERMANOVA, $P>0.05)$. These results indicated that site or orchard location had a stronger effect on microbial diversity than rootstock. Among the three variables tested (site, rootstock, and scion), only site had explanatory value for nematode community structure (PERMANOVA, F-stat $\left.=1.50, R^{2}=0.53, P=0.017\right)$. In addition, nitrate-nitrogen $\left(\mathrm{NO}_{3} \mathrm{~N}\right)$ was the only environmental factor that had explanatory value for the nematode community (Supplementary Figs. S7C and S8C).

TABLE 1

Statistical analysis of microbial richness and Shannon diversity index among sites $(n=20)$ and rootstocks $(n=8)$ using Kruskal-Wallis and one-way analysis of variance (ANOVA)

\begin{tabular}{|c|c|c|c|c|c|c|c|c|c|c|c|c|c|}
\hline \multirow{2}{*}{$\begin{array}{l}\text { Kruskal- } \\
\text { Wallis } \\
\text { test }\end{array}$} & \multicolumn{2}{|c|}{$\begin{array}{c}\text { Bacterial/ } \\
\text { archaeal } \\
\text { richness }\end{array}$} & \multirow{2}{*}{$\begin{array}{c}\begin{array}{c}\text { Fungal } \\
\text { richness }\end{array} \\
\text { Scion }\end{array}$} & \multirow{2}{*}{$\begin{array}{c}\text { One- } \\
\text { way } \\
\text { ANOVA } \\
\text { test }\end{array}$} & \multirow{2}{*}{$\begin{array}{c}\begin{array}{c}\text { Bacterial/ } \\
\text { archaeal } \\
\text { richness }\end{array} \\
\text { Scion }\end{array}$} & \multicolumn{3}{|c|}{$\begin{array}{l}\text { Bacterial/archaeal } \\
\text { Pielou's evenness }\end{array}$} & \multicolumn{2}{|c|}{$\begin{array}{c}\text { Fungal } \\
\text { richness }\end{array}$} & \multicolumn{3}{|c|}{ Fungal Pielou's evenness } \\
\hline & Site & Rootstock & & & & Site & Rootstock & Scion & Site & Rootstock & Site & Rootstock & Scion \\
\hline$x^{2}$ & 32.16 & 16.37 & 12.82 & F-stat & 1.19 & 4.17 & 4.07 & 0.82 & 3.82 & 5.08 & 1.24 & 1.16 & 0.79 \\
\hline \multirow[t]{2}{*}{$\mathrm{df}$} & 19 & 7 & 13 & df & 13 & 19 & 7 & 13 & 19 & 7 & 19 & 7 & 13 \\
\hline & & & & $R_{\text {adj }}^{2}$ & 0.05 & 0.58 & 0.33 & -0.057 & 0.55 & 0.39 & 0.09 & 0.02 & -0.06 \\
\hline
\end{tabular}


To test for biogeographic signal (e.g., distance decay), we performed Mantel tests on the bacterial/archaeal, fungal, and nematode Bray-Curtis dissimilarity matrices against geographic distance. There were no significant correlations between geographic distance and microbial or nematode beta diversity (all $P>0.05$ ). We also tested for patterns of synchrony in beta diversity among bacterial/ archaeal, fungal, and nematode communities, and found that the bacterial/archaeal community correlated with both fungal community (PROTEST, $P=0.001$ ) and nematode community (PROTEST, $P=0.009)$. However, there was no correlation detected between fungal and nematode communities (PROTEST, $P>0.05$ ).

Microbial community composition in apple root zone. The bacterial/archaeal 16S rRNA and fungal ITS gene sequences were classified into 43 phyla (146 classes) and 16 phyla (48 classes), respectively. The overall composition of bacterial/archaeal, and fungal communities across sites and rootstocks were comparable with relatively minor variation in the relative abundances of each phylum (Fig. 3). Based on the mean relative abundance, the bacterial/archaeal communities in all samples were dominated by Proteobacteria (31.45\%), Acidobacteria (18.5\%), Bacteroidetes (11.18\%), Verrucomicrobia (10.11\%), Planctomycetes (6.89\%), and Actinobacteria (6.25\%). Meanwhile, Ascomycota (43.47\%), Basidiomycota (31.49\%), Mortierellomycota (14.7\%), and an unidentified phylum (9.04\%) were the most dominant fungal phyla in the apple root zone. These are typical soil taxa and these bacterial and fungal phyla have been identified in apple root zone soil previously (Franke-Whittle et al. 2015; Singh et al. 2019; Wang et al. 2018; Zhang et al. 2013).

We prioritized members of the core microbiome of the apple root zone by exploring the relationship between taxon occupancy (e.g., the proportion of samples in which the taxa were detected) and abundance (Grady et al. 2019). Here, core microbiomes were defined as OTUs detected in all samples (occupancy $=1$; Supplementary Fig. S9). There were 383 bacterial or archaeal core taxa found in all samples that belonged to 15 phyla and represented $41.55 \%$ of the total relative abundance. Some bacterial and archaeal core taxa existed in high abundance in this study including uncultured archaeon (Nitrososphaeria) $(0.91 \%)$, bacterial taxa from phylum Acidobacteria (Subgroup 6) (0.84\%), class Deltaproteobacteria (0.71\%), family Chitinophagaceae (Bacteroidia) (0.69\%),

TABLE 2

Environmental factors that have explanatory value for the bacterial/archaeal and fungal communities were fitted into principal coordinate analysis plot (beta diversity was calculated using BrayCurtis dissimilarity indices) and tested using permutation test using "envfit" function in vegan package (v2.5-4) ${ }^{a}$

\begin{tabular}{|c|c|c|c|c|}
\hline \multirow[b]{2}{*}{ Variables } & \multicolumn{2}{|c|}{ Bacteria/archaea } & \multicolumn{2}{|c|}{ Fungi } \\
\hline & $R^{2}$ & $P$ & $R^{2}$ & $P$ \\
\hline \multicolumn{5}{|l|}{ Soil physicochemistry } \\
\hline $\mathrm{pH}$ & 0.64 & $0.001^{\star \star *}$ & 0.49 & $0.002^{\star *}$ \\
\hline Lime index & 0.66 & $0.001^{\star * *}$ & 0.52 & $0.001^{* * *}$ \\
\hline $\mathrm{Ca}$ & 0.42 & $0.005^{\star *}$ & 0.20 & 0.133 \\
\hline $\mathrm{Mg}$ & 0.34 & $0.025^{*}$ & 0.42 & $0.008^{* *}$ \\
\hline Sand & 0.30 & $0.035^{*}$ & 0.17 & 0.178 \\
\hline Silt & 0.36 & $0.016^{*}$ & 0.20 & 0.135 \\
\hline \multicolumn{5}{|l|}{ Nematode } \\
\hline Pratylenchus spp. & 0.12 & 0.302 & 0.42 & $0.006^{\star *}$ \\
\hline Tylenchus & 0.39 & $0.007^{\star *}$ & 0.32 & $0.018^{*}$ \\
\hline Scion & 0.64 & $0.023^{*}$ & 0.66 & $0.038^{*}$ \\
\hline Rootstock & 0.62 & $0.001^{\star \star \star}$ & 0.58 & $0.014^{*}$ \\
\hline
\end{tabular}

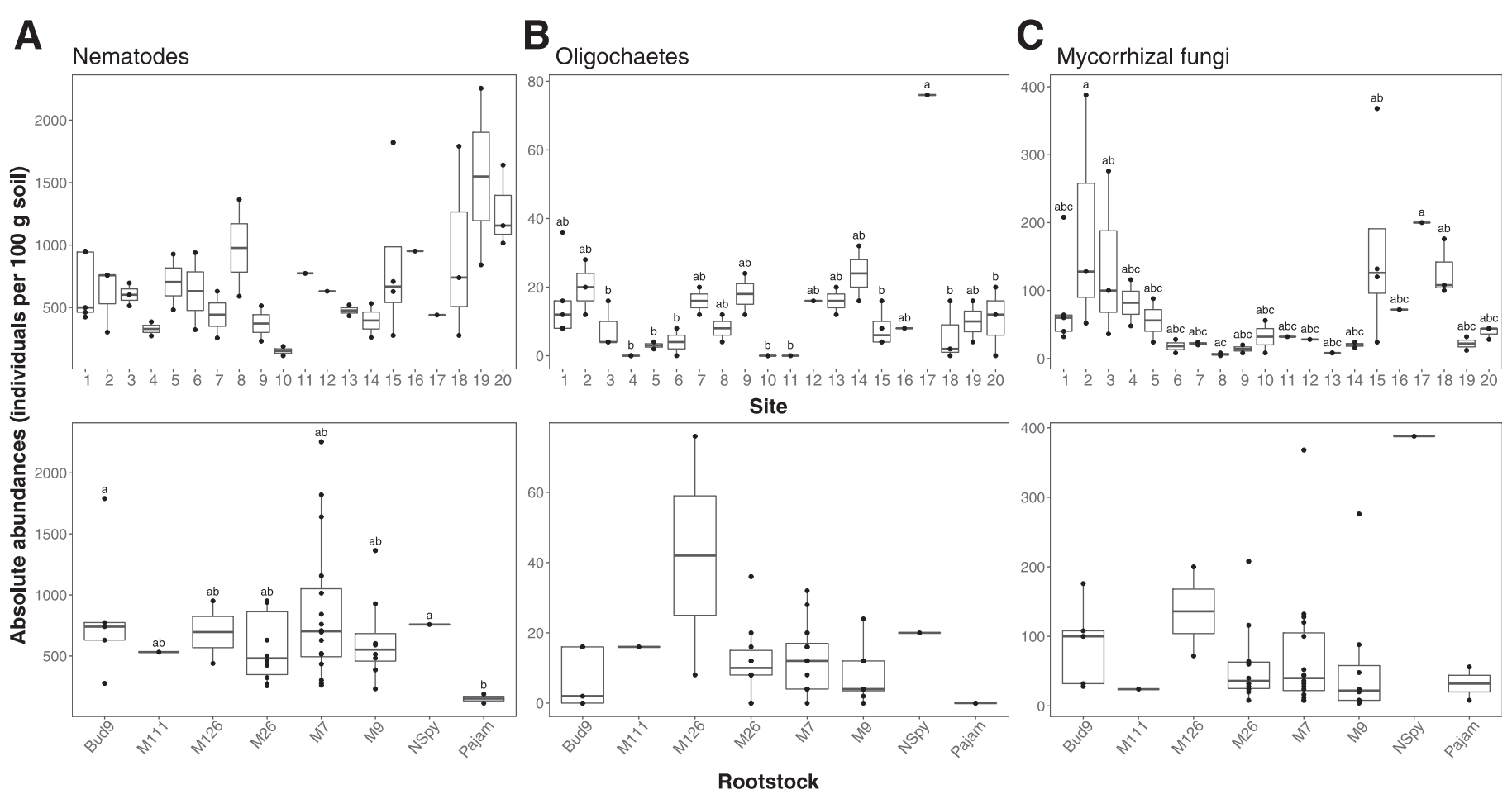

Fig. 2. Absolute A, nematode, B, oligochaetes, and C, mycorrhizal fungi abundances across sites and rootstocks. For each boxplot, circles represent measurement for each sample. The central horizontal lines represent the mean of measurements. Samples labeled with different letters are identified as significantly different based on Tukey's honestly significant difference post-hoc test. Samples with no letters are not significantly different. 
A Bacteria/archaea

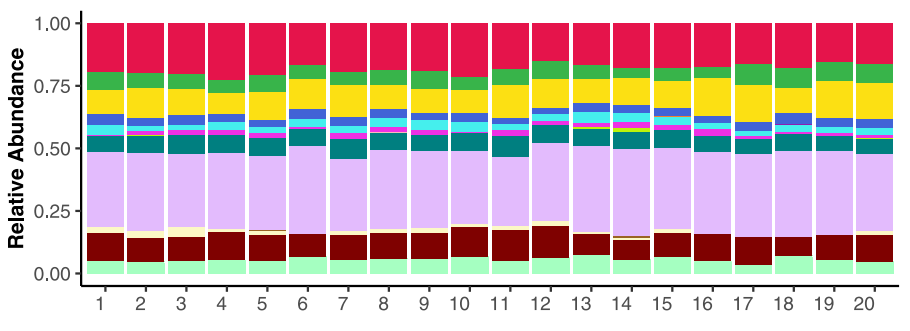

Site

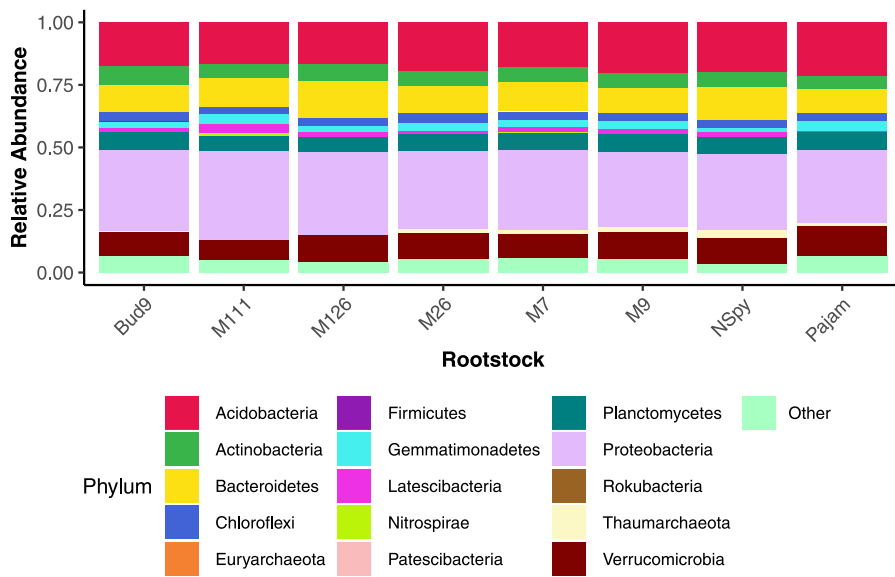

\section{B Fungi}

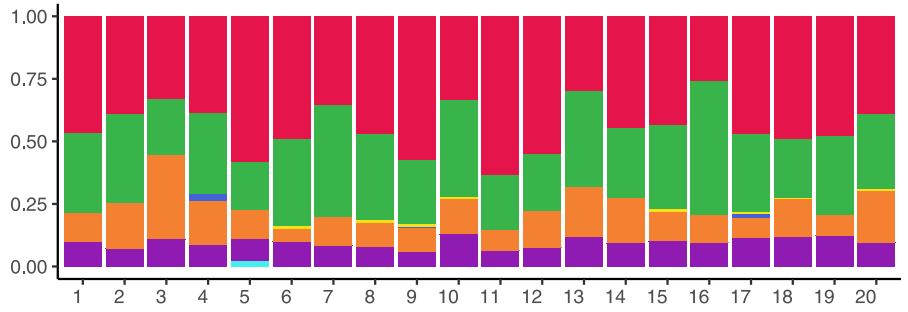

Site

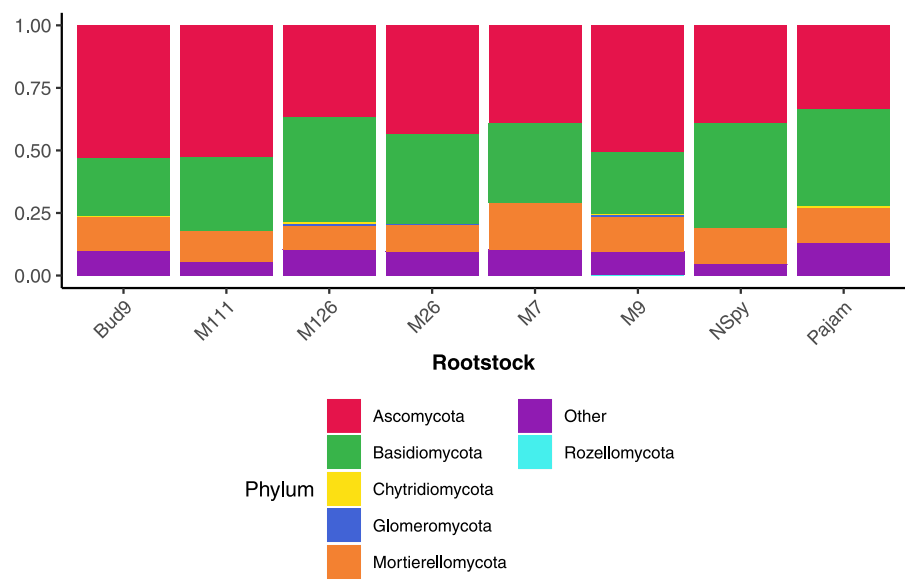

Fig. 3. The relative abundance of $\mathbf{A}$, bacterial/archaeal and $\mathbf{B}$, fungal taxa grouped at phylum level across sites and rootstocks. Taxa with relative abundance less than 0.01 and unassigned taxa or those for which taxonomic assignment could not be made past Domain were defined as "other." Bars are color-coded by phylum.

A
Bacteria/archaea

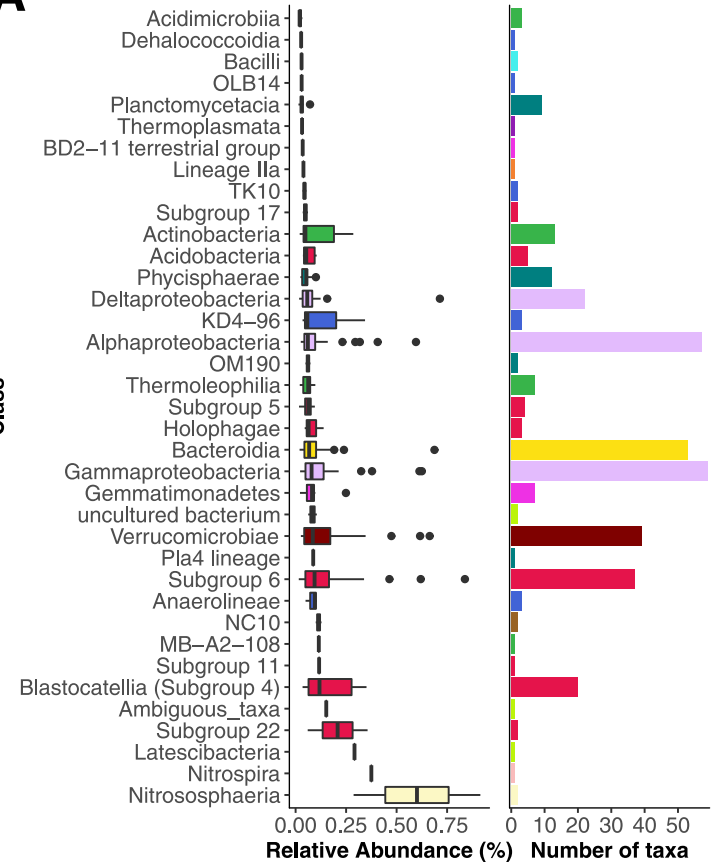

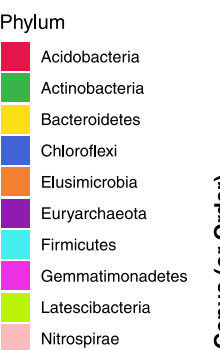

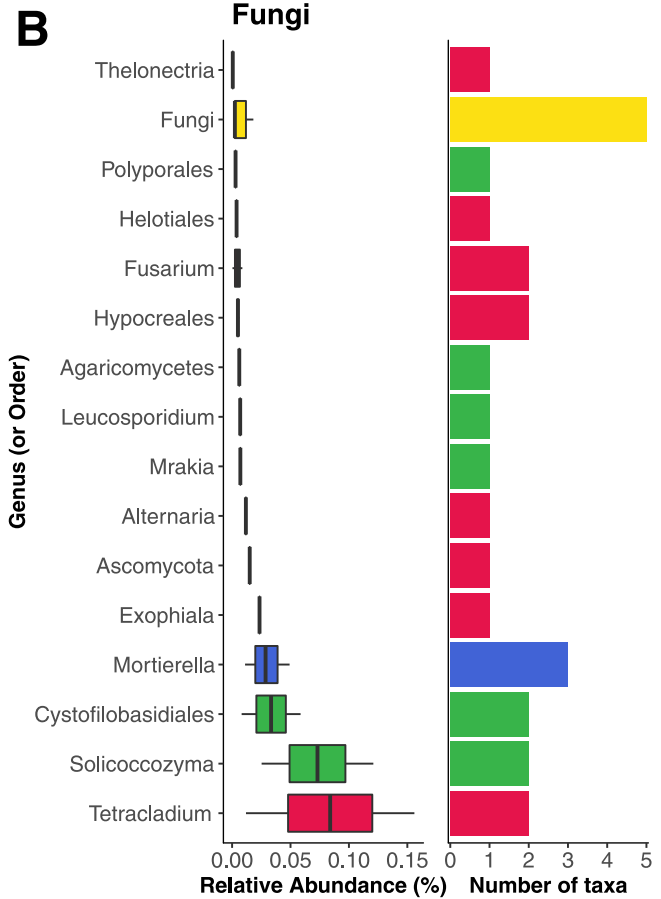

Planctomycetes

Proteobacteria

Rokubacteria

Thaumarchaeota

Verrucomicrobia Relative Abundance (\%) Number of taxa
Phylum

Ascomycota

Basidiomycota

Fungi

Mortierellomycota

Fig. 4. Bacterial/archaeal and fungal taxa with occupancy of 1 that were defined as core microbiome members. Bacterial/archaeal and fungal core taxa were classified into 15 and 3 phyla, respectively. Boxplots represent the percentage relative abundance of $\mathbf{A}$, bacterial/archaeal core taxa that are grouped by class and B, fungal taxa that are grouped by genus or order. Bars represent the number of bacterial/archaeal, and fungal core taxa are color-coded by phylum. 
genus Candidatus Udaeobacter (Verrucomicrobia) (0.66\%), Pseudomonas (Gammaproteobacteria) (0.62\%) and Bradyrhizobium (Alphaproteobacteria) $(0.59 \%)$ (Fig. 4A). Among all core bacterial and archaeal phyla, Proteobacteria (138 taxa), Acidobacteria (74 taxa), Bacteroidetes (53 taxa), and Verrucomicrobia (39 taxa) were the most abundant. Fungal core microbiome members consisted of 27 OTUs representing $60.26 \%$ of the total relative abundance that belong to Ascomycota (11 taxa), Basidiomycota (8 taxa), Mortierellomycota (3 taxa), and unidentified phyla (5 taxa) (Fig. 4B). Fungal core taxa with high abundance were Tetracladium (15.6\%), Solicoccozyma (12.1\%), Cystofilobasidiales (5.9\%), Mortierella (4.9\%), Exophiala (2.3\%), and Alternaria (1.2\%) (Fig. 4B). Finally, members of genus Fusarium registered at $100 \%$ occupancy. The high distribution of Fusarium in this study, members of which are common fungal pathogens in a variety of perennial crops, suggests that they are regionally cosmopolitan among Michigan apple orchards.

Microbial network of apple root zone. We constructed correlation networks to better understand the complex associations within and between bacteria and archaea, fungi, and nematode, mycorrhizal fungi, and oligochaete communities in the apple root zone. We used 3,321 total OTUs that were detected in more than half of the samples (23 out of 45 total samples). The network was scale-free (R-square of power-law $=0.89)$, and it had 426 nodes and 615 edges. The network showed no significant correlation of nematodes, mycorrhizal fungi, and oligochaetes with $16 \mathrm{~S}$ rRNA gene bacterial and archaeal taxa, or ITS fungal taxa. Among all nodes, 376 nodes were bacteria, 4 nodes were archaea, and 46 nodes were fungi. Bacteria-bacteria interactions dominated the networks and there were few bacteria-fungi, bacteria-archaea, and fungi-fungi associations (Fig. 5A). Positive associations were generally separated in the network from negative associations. Among the few bacteria-fungi correlations observed, the associations tended to be negative. There were 12 taxa defined as module hubs $(\mathrm{Zi}>2.5$ and $\mathrm{Pi}<0.62)$, and five taxa were connectors across modules $(\mathrm{Zi}<2.5$ and $\mathrm{Pi}>0.62$, Fig. 5B). Module hubs included Gammaproteobacteria (four OTUs), Verrucomicrobia (two OTUs), Acidobacteria (two OTUs), Chloroflexi (two OTUs), Bacteroidetes (one OTU), and Alphaproteobacteria (one OTU). Meanwhile, there were three OTUs belonging to Acidobacteria, one Deltaproteobacteria, and one unclassified OTU that identified as connectors. The majority of taxa (409 OTUs) were peripheral $(\mathrm{Zi}<2.5$ and $\mathrm{Pi}<0.62)$. Notably, there were no network hubs detected, indicating that there were no taxa with many interactions within and among modules $(\mathrm{Zi}>2.5$ and $\mathrm{Pi}>0.62)$. This agrees with our prior abundance-occupancy and beta diversity analyses that suggest no strongly dominant taxa and substantial orchard-to-orchard variability.

\section{DISCUSSION}

This study assessed multitrophic microbial communities in apple root zones in an important U.S. apple growing region and revealed their association with each other and with environmental factors. Our results show that differences in microbial community structure in the apple root zone were mainly explained by the differences in orchard location, while the edaphic properties of particular soils were associated with bacterial and fungal alpha diversity. This result is consistent with the study of Deakin et al. (2018), which reported that

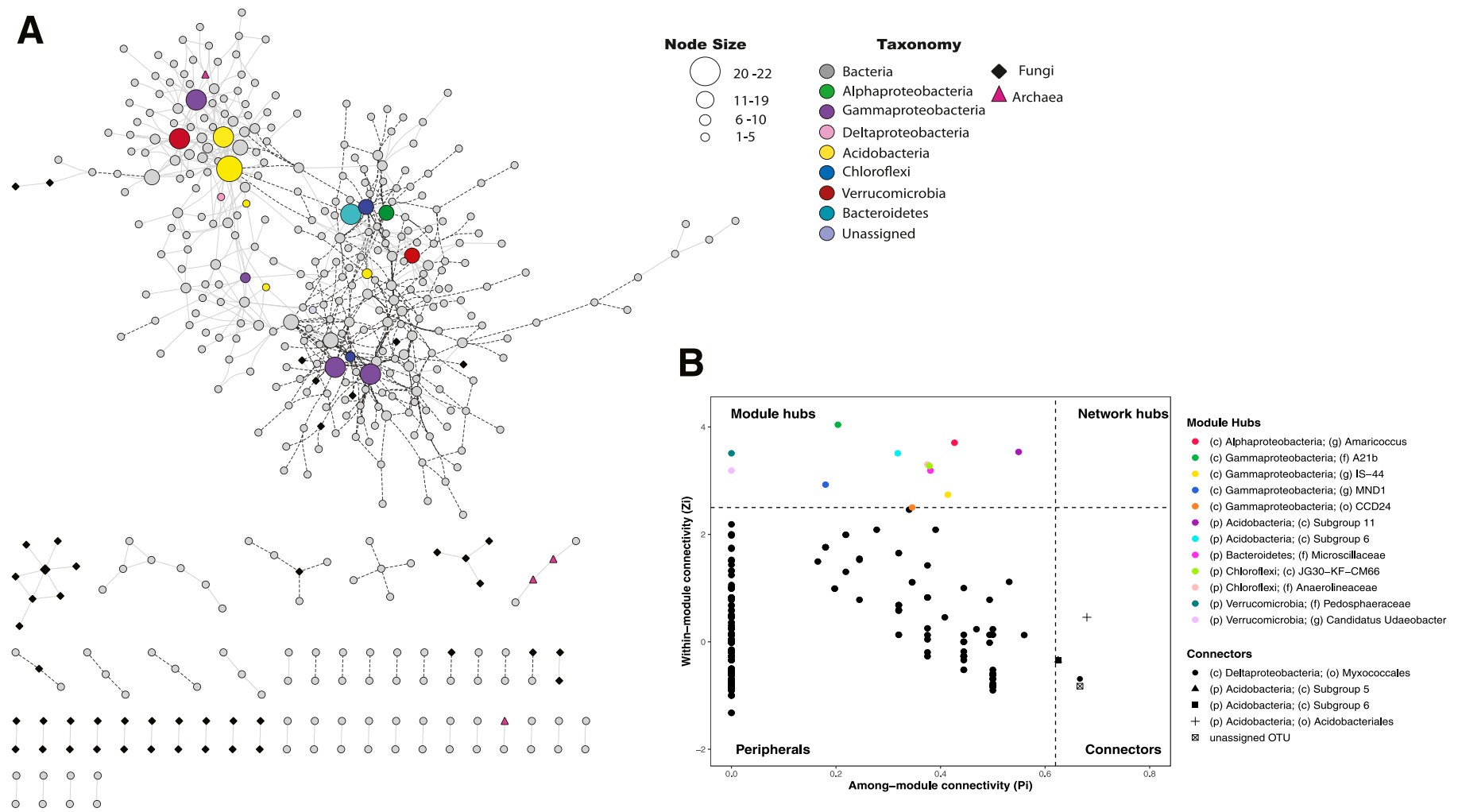

Fig. 5. A, Co-occurrence network of trophic levels in the apple root zone was dominated by bacteria-bacteria interactions and there were few bacteria-fungi and bacteria-archaea interactions. There were no interactions of nematode, mycorrhizal fungi, and oligochaetes detected in the network. Solid and dash lines indicate positive and negative interactions, respectively. Node size is determined by the number of connecting edges. A, Colored nodes are taxa belonging to the module hub and connector which may play an important role for microbial network structure. B, The within ( $\mathrm{Zi})$ and among $(\mathrm{Pi})$ module connectivity plot revealed 12 and 5 module hub and connector taxa, respectively. All module hub and connector taxa were bacteria, and the majority of taxa were peripherals. 
different orchard locations determined soil microbial community composition and structure in the United Kingdom, and with Jiang et al. (2017), which reported that soil properties and orchard location influenced microbial composition in orchards in Bohai Gulf, China. Therefore, our study confirms that different geographical sites reflect the differences of soil properties and characteristics and lead to variation in microbial diversity in apple root zones.

We found that microbial community structure in the apple root zone was also affected by the rootstock but not the scion. However, this effect was minor compared with the effect of orchard location. These results agree with previous findings reported by Rumberger et al. (2004), Yao et al. (2006), and St. Laurent et al. (2010) that bacterial and fungal composition in apple root zones were influenced by rootstock cultivar, and this has also been reported for other plants (e.g., grapevine [Marasco et al. 2018] and tomato [Poudel et al. 2019]). The rootstock is by definition in direct contact with the soil and associated soil microbes, and likely through root exudation (Zhalnina et al. 2018) shapes the microbial diversity and composition in the root zone. Transcriptomic analysis of apple rootstock planted into diseaseconducive soil revealed upregulated genes involved in secondary metabolism and plant defense, such as flavonoid, phenylpropanoid, and phenolic compounds that indicate a response to biotic stress (Weiß et al. 2017). Moreover, phenolic compounds and rhizodeposits of apple rootstocks have been proposed as a contributing factor to microbial community composition in the root zone (Leisso et al. 2017; Yim et al. 2015). In contrast, the scion is the particular cultivar grafted to the rootstock above ground and likely contributes little to the microbial communities in the root zone, though a recent study reported that different genotype combinations of scion and rootstock influenced fungal endophytic community composition of apple trees (Liu et al. 2018). Here, our study agrees again with prior work because we also detected a weak scion-rootstock interaction. Together, these results suggest that biogeography is more important in determining apple root zone communities, but that rootstock can also explain some of the variation after accounting for location.

We identified core microbiome members as bacterial, archaeal, or fungal taxa that were present in all samples. We discuss in more detail the composition of this core and what is known about their roles in soil or associations with apple in the Supplementary Material. This was a diverse group composed of over 400 taxa, which is a relatively large cohort for a core microbiome compared with our other studies that applied the abundance-occupancy approach (Grady et al. 2019; Shade and Stopnisek 2019). Also striking was that there were no strongly dominating taxa in the bacterial core, with high mean relative abundances greater than $1 \%$, and most would be considered members of the rare biosphere. Therefore, while we expected to identify a handful of tens of taxa that may be core to the apple root zone, we could not prioritize a few taxa from this large cohort. This suggests either that there are no universal bacterial and archaeal members of root zone microbiome or that functional aspects of the collection of microbes is instead more important than the membership.

Perennial tree crops, such as apple, are assumed to develop more stable interactions with microbial communities in the rhizosphere due to the relative longevity of perennial plants and lack of soil disturbances like annual rotation (Mercado-Blanco et al. 2018). Moreover, it has been suggested that microbial communities in the root zone of perennial trees are persistently affected by root exudates, which can eventually shape the microbial communities in distinctive manner from annual plants (Mercado-Blanco et al. 2018). Our study revealed that microbial community in the apple root zone had high bacterial diversity and also evenness. In addition, taxonomic identity of the core microbiome members revealed no dominance of particular taxa, which agrees with our observation of high evenness. An analysis of the root zone microbial community of apple and other fruit tree crops also reported high bacterial diversity in apple root zone (Si et al. 2018). Greater diversity and evenness was also detected in a study comparing a perennial grass (switchgrass) compared with an annual one (corn) (Hargreaves et al. 2015). Together, our study and these others hint that high diversity and evenness, and also lack of dominant core microbiome members, may be characteristic of perennial crop microbiomes.

An advance that our study offers for characterizing the healthy apple root zone microbiome is that we have quantified several trophic levels and related their dynamics to one another, including bacteria and archaea, fungi, and nematodes. On balance, we did not find evidence of strong correlative associations between trophic levels. We observed concordance in the beta diversity and overarching biogeographic patterns between bacteria and fungi and between bacteria and nematodes (but not between fungi and nematodes), but the network analyses suggested few associations between particular taxa from these communities. For example, there were no interactions detected between nematode and microbial taxa, even though the PCoA showed that nematodes Tylenchus and Pratylenchus spp. had explanatory value for microbial community structure. The few network associations between bacteria and fungi were negative. However, network analyses should be interpreted carefully because they are hypothesis generating tools (Faust and Raes 2012), and second, may not capture known biological interactions (Hirano and Takemoto 2019). However, our study does not provide evidence that there are many or strong intertrophic relationships that define the apple root zone microbiome.

In conclusion, our assessment of the microbial community structure and network of apple root zones revealed the complex associations among microbial members. Our study showed that the microbial community in apple root zones was strongly influenced by orchard location. Rootstock was also a minor but significant factor that contributed to the microbial community structure. In this study, we identified key belowground players and their possible interactions in Michigan apple orchards. The apple root zone microbial community showed diversity and structure typical of perennial crops, with high diversity and high evenness and many rare core microbiome members. However, we did not detect particular taxa and/or specific patterns of intertrophic interactions that were characteristic of apple root zone soil. This is the first study to evaluate multiple trophic levels of apple orchard microbiome community through network analysis. This work can be used to inform "baseline" microbiome community structure and biogeography in the root zone, and in the future could be compared with unhealthy trees to determine any sitespecific taxonomic shifts that are associated with tree health.

\section{ACKNOWLEDGMENTS}

We thank Amy Irish-Brown for putting us in contact with all of the growers who graciously allowed us to conduct this study on their respective farms and we thank the JKW and MAQ-T labs for field and technical support.

\section{LITERATURE CITED}

Caporaso, J. G., Kuczynski, J., Stombaugh, J., Bittinger, K., Bushman, F. D., Costello, E. K., Fierer, N., Peña, A. G., Goodrich, J. K., Gordon, J. I., Huttley, G. A., Kelley, S. T., Knights, D., Koenig, J. E., Ley, R. E., Lozupone, C. A., McDonald, D., Muegge, B. D., Pirrung, M., Reeder, J., Sevinsky, J. R., Turnbaugh, P. J., Walters, W. A., Widmann, J., Yatsunenko, T., Zaneveld, J., and Knight, R. 2010. Qiime allows analysis on high-throughput community sequencing data. Nat. Methods 7:335-336.

Caporaso, J. G., Lauber, C. L., Walters, W. A., Berg-Lyons, D., Lozupone, C. A., Turnbaugh, P. J., Fierer, N., and Knight, R. 2011. Global patterns of $16 \mathrm{~S}$ rRNA diversity at a depth of millions of sequences per sample. Proc. Natl. Acad. Sci. 108:4516-4522. 
Chapelle, E., Mendes, R., Bakker, P. A. H., and Raaijmakers, J. M. 2016. Fungal invasion of the rhizosphere microbiome. ISME J. 10:265-268.

Cole, J. R., Wang, Q., Fish, J. A., Chai, B., McGarrell, D. M., Sun, Y., Brown, C. T., Porras-Alfaro, A., Kuske, C. R., and Tiedje, J. M. 2014. Ribosomal Database Project: Data and tools for high throughput rRNA analysis. Nucleic Acids Res. 42:D633-D642.

Deakin, G., Tilston, E. L., Bennett, J., Passey, T., Harrison, N., FernándezFernández, F., and Xu, X. 2018. Spatial structuring of soil microbial communities in commercial apple orchards. Appl. Soil Ecol. 130:1-12.

Deng, Y., Jiang, Y. H., Yang, Y., He, Z., Luo, F., and Zhou, J. 2012. Molecular ecological network analyses. BMC Bioinformatics 13:113.

Edgar, R. C. 2010. Search and clustering orders of magnitude faster than BLAST. Bioinformatics 26:2460-2461.

Edgar, R. C. 2013. UPARSE: Highly accurate OTU sequences from microbial amplicon reads. Nat. Methods 10:996-998.

Edgar, R. C. 2016. SINTAX: A simple non-Bayesian taxonomy classifier for $16 \mathrm{~S}$ and ITS sequences. bioRxiv 74161.

Edgar, R. C., and Flyvbjerg, H. 2015. Error filtering, pair assembly and error correction for next-generation sequencing reads. Bioinformatics 31:3476-3482.

Faust, K., and Raes, J. 2012. Microbial interactions: From networks to models. Nat. Rev. Microbiol. 10:538-550.

Franke-Whittle, I. H., Manici, L. M., Insam, H., and Stres, B. 2015. Rhizosphere bacteria and fungi associated with plant growth in soils of three replanted apple orchards. Plant Soil 395:317-333.

Gdanetz, K., Benucci, G. M. N., Vande Pol, N., and Bonito, G. 2017. CONSTAX: A tool for improved taxonomic resolution of environmental fungal ITS sequences. BMC Bioinformatics 18:538.

Gihring, T. M., Green, S. J., and Schadt, C. W. 2012. Massively parallel rRNA gene sequencing exacerbates the potential for biased community diversity comparisons due to variable library sizes. Environ. Microbiol. 14:285-290.

Grady, K. L., Sorensen, J. W. S., Stopnisek, N., Guittar, J., and Shade, A. 2019. Assembly and seasonality of core phyllosphere microbiota on perennial biofuel crops. Nat. Commun. 10:4135.

Guillot, G., and Rousset, F. 2013. Dismantling the Mantel tests. Methods Ecol. Evol. 4:336-344.

Hargreaves, S. K., Williams, R. J., and Hofmockel, K. S. 2015. Environmental filtering of microbial communities in agricultural soil shifts with crop growth. PLoS One 10:e0134345.

Hirano, H., and Takemoto, K. 2019. Difficulty in inferring microbial community structure based on co-occurrence network approaches. BMC Bioinformatics 20:329.

Jenkins, W. R. 1983. A rapid centrifugal-flotation technique for separating nematodes from soil. Plant Dis. Rep. 48:692.

Jiang, J., Song, Z., Yang, X., Mao, Z., Nie, X., Guo, H., and Peng, X. 2017. Microbial community analysis of apple rhizosphere around Bohai Gulf. Sci. Rep. 7:8918.

Kõljalg, U., Nilsson, R. H., Abarenkov, K., Tedersoo, L., Taylor, A. F. S., Bahram, M., Bates, S. T., Bruns, T. D., Bengtsson-Palme, J., Callaghan, T. M., Douglas, B., Drenkhan, T., Eberhardt, U., Dueñas, M., Grebenc, T., Griffith, G. W., Hartmann, M., Kirk, P. M., Kohout, P., Larsson, E., Lindahl, B. D., Lücking, R., Martín, M. P., Matheny, P. B., Nguyen, N. H., Niskanen, T., Oja, J., Peay, K. G., Peintner, U., Peterson, M., Põldmaa, K., Saag, L., Saar, I., Schüßler, A., Scott, J. A., Senés, C., Smith, M. E., Suija, A., Taylor, D. L., Telleria, M. T., Weiss, M., and Larsson, K.-H. 2013. Towards a unified paradigm for sequence-based identification of fungi. Mol. Ecol. 22:5271-5277.

Lee, S. H., Sorensen, J. W., Grady, K. L., Tobin, T. C., and Shade, A. 2017. Divergent extremes but convergent recovery of bacterial and archaeal soil communities to an ongoing subterranean coal mine fire. ISME J. 11: 1447-1459.

Leisso, R., Rudell, D., and Mazzola, M. 2017. Metabolic composition of apple rootstock rhizodeposits differs in a genotype-specific manner and affects growth of subsequent plantings. Soil Biol. Biochem. 113:201-214.

Liu, J., Abdelfattah, A., Norelli, J., Burchard, E., Schena, L., Droby, S., and Wisniewski, M. 2018. Apple endophytic microbiota of different rootstock/ scion combinations suggests a genotype-specific influence. Microbiome 6:18.

Marasco, R., Rolli, E., Fusi, M., Michoud, G., and Daffonchio, D. 2018. Grapevine rootstocks shape underground bacterial microbiome and networking but not potential functionality. Microbiome 6:3.

Martin, M. 2011. Cutadapt removes adapter sequences from high-throughput sequencing reads. EMBnet. J. 17:10-12.

McMurdie, P. J., and Holmes, S. 2013. Phyloseq: An R package for reproducible interactive analysis and graphics of microbiome census data. PLoS One 8: e61217.
Meena, K. K., Sorty, A. M., Bitla, U. M., Choudhary, K., Gupta, P., Pareek, A., Singh, D. P., Prabha, R., Sahu, P. K., Gupta, V. K., Singh, H. B., Krishanani, K. K., and Minhas, P. S. 2017. Abiotic stress responses and microbe-mediated mitigation in plants: The omics strategies. Front. Plant Sci. 8:172.

Mercado-Blanco, J., Abrantes, I., Caracciolo, A. B., Bevivino, A., Ciancio, A., Grenni, P., Hrynkiewicz, K., Kredics, L., and Proença, D. N. 2018.

Belowground microbiota and the health of tree crops. Front. Microbiol. 9: 1006.

Oksanen, J. 2015. Multivariate analysis of ecological communities in R: vegan tutorial. R Package Version 2.5-4.

Oksanen, J., Blanchet, F. G., Friendly, M., Kindt, R., Legendre, P., Mcglinn, D., Minchin, P. R., O'Hara, R. B., Simpson G. L., Solymos, P., Stevens, M. H. H., Szoecs, E., and Wagner, H. 2019. Package "vegan": Community Ecology Package. 2.5-6. https://CRAN.R-project.org/package=vegan

Panke-Buisse, K., Poole, A. C., Goodrich, J. K., Ley, R. E., and Kao-Kniffin, J. 2015. Selection on soil microbiomes reveals reproducible impacts on plant function. ISME J. 9:980-989.

Poudel, R., Jumpponen, A., Kennelly, M. M., Rivard, C. L., Gomez-Montano, L., and Garrett, K. A. 2019. Rootstocks shape the rhizobiome: Rhizosphere and endosphere bacterial communities in the grafted tomato system. Appl. Environ. Microbiol. 85:e01765-e18.

Quast, C., Pruesse, E., Yilmaz, P., Gerken, J., Schweer, T., Yarza, P., Peplies, J., and Glöckner, F. O. 2013. The SILVA ribosomal RNA gene database project: Improved data processing and web-based tools. Nucleic Acids Res.: D590-D596.

Rumberger, A., Yao, S., Merwin, I. A., Nelson, E. B., and Thies, J. E. 2004. Rootstock genotype and orchard replant position rather than soil fumigation or compost amendment determine tree growth and rhizosphere bacterial community composition in an apple replant soil. Plant Soil 264:247-260.

Shade, A., and Stopnisek, N. 2019. Abundance-occupancy distributions to prioritize plant core microbiome membership. Curr. Opin. Microbiol. 49: 50-58.

Shannon, P., Markiel, A., Ozier, O., Baliga, N. S., Wang, J. T., Ramage, D., Amin, N., Schwikowski, B., and Ideker, T. 2003. Cytoscape: A software environment for integrated models of biomolecular interaction networks. Genome Res. 13:2498-2504.

Si, P., Shao, W., Yu, H., Yang, X., Gao, D., Qiao, X., Wang, Z., and Wu, G. 2018. Rhizosphere microenvironments of eight common deciduous fruit trees were shaped by microbes in Northern China. Front. Microbiol. 9:3147.

Singh, J., Silva, K. J. P., Fuchs, M., and Khan, A. 2019. Potential role of water, soil and plant microbial communities in rapid decline of apple trees. PLoS One 14:e0213293.

Smith, D. P., and Peay, K. G. 2014. Sequence depth, not PCR replication, improves ecological inference from next generation DNA sequencing. PLoS One 9:e90234.

St. Laurent, A., Merwin, I. A., Fazio, G., Thies, J. E., and Brown, M. G. 2010. Rootstock genotype succession influences apple replant disease and rootzone microbial community composition in an orchard soil. Plant Soil 337: 259-272.

Sugiyama, A., Bakker, M. G., Badri, D. V., Manter, D. K., and Vivanco, J. M. 2013. Relationships between Arabidopsis genotype-specific biomass accumulation and associated soil microbial communities. Botany 91:123-126.

Thakur, M. P., and Geisen, S. 2019. Trophic regulations of the soil microbiome. Trends Microbiol. 27:771-780.

U.S. Department of Agriculture-National Agricultural Statistics Service. 2019. Noncitrus fruits and nuts 2018 summary. USDA-NASS. https:// www.nass.usda.gov/Publications/Todays_Reports/reports/ncit0619.pdf

Wang, G., Yin, C., Pan, F., Wang, X., Xiang, L., Wang, Y., Wang, J., Tian, C., Chen, J., and Mao, Z. 2018. Analysis of the fungal community in apple replanted soil around Bohai Gulf. Hortic. Plant J. 4:175-181.

Wang, Q., Garrity, G. M., Tiedje, J. M., and Cole, J. R. 2007. Naïve Bayesian classifier for rapid assignment of rRNA sequences into the new bacterial taxonomy. Appl. Environ. Microbiol. 73:5261-5267.

Wei, Z., Yang, T., Friman, V. P., Xu, Y., Shen, Q., and Jousset, A. 2015. Trophic network architecture of root-associated bacterial communities determines pathogen invasion and plant health. Nat. Commun. 6:8413.

Weidner, S., Koller, R., Latz, E., Kowalchuk, G., Bonkowski, M., Scheu, S., and Jousset, A. 2015. Bacterial diversity amplifies nutrient-based plant-soil feedbacks. Funct. Ecol. 29:1341-1349.

Weiß, S., Bartsch, M., and Winkelmann, T. 2017. Transcriptomic analysis of molecular responses in Malus domestica 'M26' roots affected by apple replant disease. Plant Mol. Biol. 94:303-318. 
Weiss, S., Xu, Z. Z., Peddada, S., Amir, A., Bittinger, K., Gonzalez, A., Lozupone, C., Zaneveld, J. R., Vázquez-Baeza, Y., Birmingham, A., Hyde, E. R., and Knight, R. 2017. Normalization and microbial differential abundance strategies depend upon data characteristics. Microbiome 5:27.

Yao, S., Merwin, I. A., Abawi, G. S., and Thies, J. E. 2006. Soil fumigation and compost amendment alter soil microbial community composition but do not improve tree growth or yield in an apple replant site. Soil Biol. Biochem. 38: 587-599.

Yim, B., Winkelmann, T., Ding, G. C., and Smalla, K. 2015. Different bacterial communities in heat and gamma irradiation treated replant disease soils revealed by $16 \mathrm{~S}$ rRNA gene analysis-contribution to improved aboveground apple plant growth? Front. Microbiol. 6:1224.

Zhalnina, K., Louie, K. B., Hao, Z., Mansoori, N., Da Rocha, U. N., Shi, S., Cho, H., Karaoz, U., Loqué, D., Bowen, B. P., Firestone, M. K., Northen, T. R., and Brodie, E. L. 2018. Dynamic root exudate chemistry and microbial substrate preferences drive patterns in rhizosphere microbial community assembly. Nat. Microbiol. 3:470-480.

Zhang, Q., Sun, J., Liu, S., and Wei, Q. 2013. Manure refinement affects apple rhizosphere bacterial community structure: A study in sandy soil. PLoS One 8:e76937. 